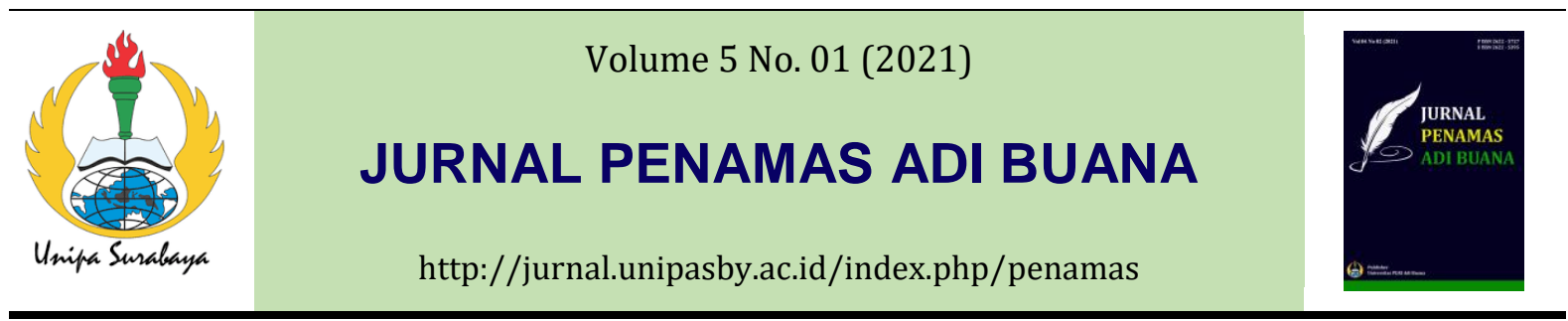

\title{
PEMANFAATAN TEKNOLOGI DI ERA NEW NORMAL UNTUK PEMBELAJARAN SPEAKING DAN LISTENING BAGI GURU -GURU SMA/SMK KOTA SURABAYA
}

\author{
Nukmatus Syahria ${ }^{1 *}$, Irfan Rifai ${ }^{2}$, Ferra Dian Andanty ${ }^{3}$, Salim Nabhan ${ }^{4}$ \\ ${ }^{1}$ Program Studi Pendidikan Bahasa Inggris, Universitas PGRI Adi Buana Surabaya, Indonesia \\ *Email: syahria@unipasby.ac.id
}

\begin{tabular}{|c|c|}
\hline Informasi Artikel & Abstrak \\
\hline $\begin{array}{l}\text { Kata kunci: } \\
\text { Podcast, Audacity, New } \\
\text { Normal, Listening, } \\
\text { Speaking }\end{array}$ & $\begin{array}{l}\text { Pemanfaatan teknologi khususnya dalam pembelajaran Bahasa Inggris di } \\
\text { Indonesia sudah banyak dieksplorasi. Sebagian besar hasil eksplorasi ini } \\
\text { mengungkapkan bahwa teknologi dapat memfasilitasi para siswa dalam } \\
\text { menguasai materi dan meningkatkan keterampilan berbahasa mereka. } \\
\text { Selaras dengan hasil penemuan tersebut, dosen Prodi Bahasa Inggris } \\
\text { Universitas PGRI Adi Buana Surabaya menyelenggarakan Pengabdian Pada } \\
\text { Masyarakat (PPM) berupa pelatihan pemanfaatan Podcast dengan bantuan } \\
\text { aplikasi Audacity dalam pengajaran Listening dan Speaking bagi guru } \\
\text { SMA/SMK kota Surabaya. PPM ini dilaksanakan secara daring dan diikuti } \\
\text { oleh } 95 \text { guru. Setelah selesai PPM, kami ingin mengetahui pandangan guru- } \\
\text { guru tersebut mengenai pemanfaatan Podcast dan Audacity dalam } \\
\text { pembelajaran Listening dan Speaking. Pre-Test dan kuisioner digunakan } \\
\text { untuk mengumpulkan data. Data dari pre-test dan kuisioner ditambah } \\
\text { dengan data opini tertulis peserta dianalisis menggunakan konten analisis. } \\
\text { Hasil analisis data menunjukkan bahwa } 75 \text { peserta mempunyai sikap yang } \\
\text { positif terhadap penggunaan Podcast dalam pembelajaran Listening dan } \\
\text { Speaking. Hal utama yang mendasari sikap positif mereka adalah } \\
\text { fleksibilitas Podcast dalam penggunaannya, fleksibilitas akses, fleksibilitas } \\
\text { frekuensi, dan fleksibilitas individu.Lebih lanjut, menurut } 80 \text { peserta, } \\
\text { aplikasi Podcast dan Audacity ini sangat mudah digunakan dan Podcast } \\
\text { juga merupakan media pembelajaran Bahasa Inggris yang menyenangkan. } \\
\text { Abstract }\end{array}$ \\
\hline $\begin{array}{l}\text { Keywords : } \\
\text { Podcast, Audacity, New } \\
\text { Normal, Listening, }\end{array}$ & $\begin{array}{l}\text { The use of technology, especially in learning English in Indonesia, has been } \\
\text { widely explored. Most of the results of this exploration revealed that } \\
\text { technology can facilitate students in mastering the material and improving } \\
\text { their language skills. In line with these findings, the lecturers of the English } \\
\text { Language Study Program at the University of PGRI Adi Buana Surabaya } \\
\text { held a Community Service Program (PPM) in the form of Podcast } \\
\text { utilization training with the help of the Audacity application in teaching } \\
\text { Listening and Speaking for SMA / SMK Surabaya city teachers. This PPM } \\
\text { was carried out online and was attended by } 95 \text { teachers. After completing } \\
\text { the PPM program, we want to know the teachers' view regarding the use of } \\
\text { Podcasts and Audacity in Listening and Speaking. Pre-Test and } \\
\text { questionnaire were used to collect data. Data from pre-test and }\end{array}$ \\
\hline
\end{tabular}


questionnaire as well as data from participant's written opinion were analyzed using content analysis. The results of data analysis showed that 75 participants had a positive attitude towards the use of Podcasts in Listening and Speaking learning. The main thing that underlies their positive attitude is the flexibility of Podcast in its use, flexibility of access, flexibility of frequency, and individual flexibility. Furthermore, according to 80 participants, the Podcast and Audacity applications are very easy to use and Podcast is also a fun media for learning English.

\section{PENDAHULUAN}

Bahasa Inggris telah dimasukkan ke dalam kurikulum pendidikan di Indonesia dan telah diajarkan semenjak di sekolah Taman kanak-kanak dan tingkat Sekolah Dasar sebagai muatan lokal. Walaupun Bahasa Inggris telah lama diajarkan, akan tetapi banyak dari siswa yang merasa kesulitan menguasai Bahasa Inggris khususnya pada pelajaran Listening dan Speaking di tingkat Sekolah Menengah Atas (SMA). Seperti yang terjadi di banyak Sekolah Menengah Atas di Surabaya, banyak sekali dari para murid SMA yang kurang percaya diri dalam hal berbicara menggunakan Bahasa Inggris serta mengungkapkan ide-idenya dalam Bahasa Inggris. Hal ini dibuktikan saat mereka harus menghadapi ujian masuk Perguruan Tinggi, mereka mengalami kesulitan saat menjalani tes Listening. Banyak dari mereka yang gagal masuk ujian perguruan tinggi dikarenakan nilai mereka dibawah minimal dan saat masuk di jurusan Bahasa Inggris banyak dari mereka yang gagal di tes Speaking.

Para guru-guru SMA/ SMK di Surabaya banyak yang mengeluhkan siswa-siswi SMA dan SMK yang kurang percaya diri saat pelajaran Speaking dan rendahnya nilai mereka saat ada quiz atau latihan Listening. Dalam hal ini, para guru seyogyanya diharapkan mampu mengajarkan Listening dan Speaking dengan cara yang lebih kreatif dan menyenangkan agar para siswa dapat dengan mudah memahami dan menguasai kecakapan dalam Listening dan Speaking. Dan untuk mengatasi kesulitan belajar siswa dalam pelajaran Listening dan Speaking, para guru dapat mengaplikasikan strategistrategi pembelajaran berbasis teknologi yang lebih ekonomis serta lebih menarik minat siswa khususnya generasi milenial.

Pengajaran Bahasa Inggris khususnya di era New Normal ini menuntut lebih banyak kreativitas agar para siswa tidak merasa bosan karena seringnya belajar online di rumah dan hanya mengerjakan tugas-tugas dari guru saja. Menurut Karagiorgi \& Symeou, 2005 saat ini proses pembelajaran dimaknai sebagai sebuah proses yang konstruktif, pembelajaran mandiri, kooperatif dan berbeda untuk setiap individu. Pengajaran Listening dan Speaking membutuhkan media-media yang interaktif yang dapat membuat pengajaran menjadi lebih hidup dan bermakna. Teknologi telah menjadi bagian yang tak terpisahkan dari kehidupan kita selama beberapa dekade terakhir, khususnya di era New Normal pandemi Covid-19 ini dan membawa banyak dampak kemajuan. Kemajuan ini juga telah membuka era baru bagi dunia pendidikan dan memberikan banyak pilihan bagi para guru dan siswa dalam proses belajar mengajar. 
Tantangan dalam mengajar Listening dan Speaking saat ini dipahami sebagai strategi baru yang dapat berkontribusi terhadap kegiatan Listening dan Speaking secara efektif dan sebaiknya didukung oleh ketersediaan teknologi bagi pembelajar bahasa untuk dapat meningkatkan keterampilan Listening dan Speaking mereka. Untuk menjawab tantangan tersebut, para guru dapat menerapkan aplikasi audio recorder Podcast dan Audio Editor application untuk mengajarkan Listening dan Speaking secara lebih interaktif. Podcast menawarkan kemudahan, kesederhanaan dan efektivitas waktu yang memungkinkan siswa untuk mendengarkan materi bahasa Inggris berulang kali kapan saja dan di mana saja (Abdous et al., 2009). Lebih lanjut, Ramli \& Kurniawan, 2018 membuktikan bahwa materi dalam Podcast dapat menstimulasi siswa untuk belajar secara aktif serta dapat menambah banyak kosakata. Fitria et al., 2015 menambahkan bahwa Podcast memberi kemudahan siswa dalam berlatih Listening sekaligus juga dapat membantu meningkatkan kemampuan berbicara mereka.

Maka dari itu, dalam kesempatan PPM dosen kali ini, para tim dosen Program Studi Bahasa Inggris Universitas PGRI Adi Buana Surabaya mengadakan pelatihan dalam penggunaan Podcast dan Audacity yang bertujuan memberikan penyuluhan dan pelatihan kepada guru-guru Bahasa Inggris SMA/SMK yang ada di Surabaya tentang penerapan teknologi dalam pengajaran Listening dan Speaking.

\section{METODE PELAKSANAAN}

Dalam pelatihan ini, kami menggunakan aplikasi Podcast dan Audacity sebagai media untuk mengajar Speaking dan Listening di era New Normal pandemi COVID-19 ini, yang mana pengajaran lebih difokuskan pada metode pengajaran daring dibandingkan luring. Pelatihan ini dimaksudkan sebagai sarana untuk memberikan wawasan kepada para guru Bahasa Inggris agar mereka dapat meningkatkan kualitas pengajaran Speaking dan Listening, dikarenakan masih banyak siswa yang mengalami kesulitan dalam menguasai kedua keterampilan tersebut. Pada kegiatan PPM dosen kali ini terdapat 95 guru Bahasa Inggris dari SMA/SMK se-Kodya Surabaya yang hadir dalam penyuluhan.

Sebelum PPM dilaksanakan, kami mengadakan pre-test melalui Google forms untuk mengetahui sejauh mana wawasan guru tentang aplikasi Podcast dan Audacity untuk pembelajaran Bahasa Inggris. Ada 5 macam pertanyaan pada survei tersebut, seperti pertanyaan tentang bagaimana strategi guru-guru dalam mengajar Speaking dan Listening di era New Normal ini, bagaimana mereka mengaplikasikan strategi tersebut, apakah strategi tersebut dapat meningkatkan hasil belajar Bahasa Inggris siswa, apakah para guru mengenal aplikasi Podcast/ Audacity, bagaimana mereka mengaplikasikan media tersebut dalam pengajaran Bahasa Inggris dan kendala-kendala apa yang ditemukan saat mereka menggunakan aplikasi tersebut.

Setelah itu, kami mengadakan penyuluhan penggunaan aplikasi Podcast dan Audacity, kemudian di akhir penyuluhan kami melaksanakan sesi tanya jawab. Untuk mendapatkan sertifikat 32 JP, para peserta diwajibkan mengikuti pelatihan tentang penggunaan aplikasi Audacity dan Podcast. 
Di akhir penyuluhan, kami membagikan kuisioner yang berisi tanggapan mereka terhadap penyuluhan tersebut. Selanjutnya, kami juga meminta para peserta untuk menuliskan pengalaman serta opini mereka tentang pelatihan yang mereka ikuti, tentang kesulitan-kesulitan serta keuntungan yang mereka dapatkan setelah mengikuti pelatihan tersebut, di dalam sebuah lembar refleksi.

\section{HASIL DAN PEMBAHASAN}

\section{Pelatihan Aplikasi Podcast dan Audacity.}

Pelatihan Podcast dan Audacity ini berlangsung selama 3 kali pertemuan. Pertemuan pertama adalah penyuluhan tentang penggunaan aplikasi Podcast dan Audacity. Pertemuan kedua yaitu praktek bagaimana menggunakan aplikasi Podcast untuk pembelajaran Listening dan Speaking dan di pertemuan ketiga peserta diajarkan bagaimana mengoperasikan audio editing Audacity. Kebanyakan dari para peserta memberikan respon yang positif terhadap pelatihan ini. Dari 95 peserta 75 peserta berpendapat bahwa topik yang disampaikan sangat menarik dan sangat membantu mereka dalam mendesain materi Listening dan Speaking mereka. Sementara itu, 80 peserta berpendapat bahwa aplikasi Podcast dan Audacity ini sangat mudah digunakan dan menurut mereka Podcast merupakan media pembelajaran Bahasa Inggris yang menyenangkan.

"Saya berpikir akan menerapkan Podcast pada pembelajaran Listening dan Speaking, dikarenakan pembelajaran dengan metode ini sangatlah unik dan kreatif dan siswa juga dapat dengan mudah melakukan pembelajaran Listening dan Speaking dari rumah dengan lebih menyenangkan". (P32)

"Saya baru saja mengenal Podcast dan saya langsung jatuh cinta. Aplikasinya sangat mudah digunakan. Pembelajaran jadi lebih mudah dan menyenangkan dan saya pikir kemampuan pemahaman Listening serta Speaking siswa dapat ditingkatkan setiap waktu melalui Podcast”. (P50)

Podcast merupakan salah satu alternatif pembelajaran Listening dan Speaking yang efisien dan efektif untuk diterapkan di era pandemi Covid-19 ini selain juga menawarkan pembelajaran Speaking dan Listening yang lebih autentik dan menyesuaikan dengan tingkat kemampuan siswa.

"Menurut saya melalui Podcast siswa dapat memperoleh pengalaman belajar secara lebih autentik karena siswa dihadapkan pada pengalaman mendengarkan suara penutur asli bahasa Inggris. Hal ini memungkinkan siswa untuk dapat menguasai kosakata (vocabulary) dan pelafalan (pronunciation) dari bahasa target dengan lebih baik". (P15)

"Selain menyenangkan dan mudah diaplikasikan, aplikasi Podcast juga menawarkan beberapa manfaat dan kemudahan, misalnya siswa dapat memilih topik sesuai minat mereka dan mereka juga dapat menyesuaikan tingkat kesulitan belajar sesuai dengan level pemahaman mereka dari tingkat pemula hingga lanjut". (P8) 
Lebih lanjut, aplikasi Podcast tidak hanya meningkatkan motivasi siswa belajar, tetapi juga menumbuhkan kemandirian dalam belajar dimana kurikulum pendidikan saat ini menerapkan strategi pembelajaran berbasis masalah (problem-based learning strategy).

"Dengan menggunakan Podcast, siswa dapat mengakses materi sendiri setiap saat dan dimana saja. Dan materi- materi itu dapat diulang kapan saja. Inilah keunggulan Podcast. Siswa yang belum menguasai materi dapat setiap saat mengulang kembali materi yang ada. Materi-materi yang ada di Podcast menumbuhkan cara berpikir kritis (critical thinking) para siswa sebab materi- materi tersebut sifatnya autentik dimana siswa dapat diajari untuk memecahkan masalah-masalah yang ada terkini serta bagaimana memahami sebuah konsep”. (P75)
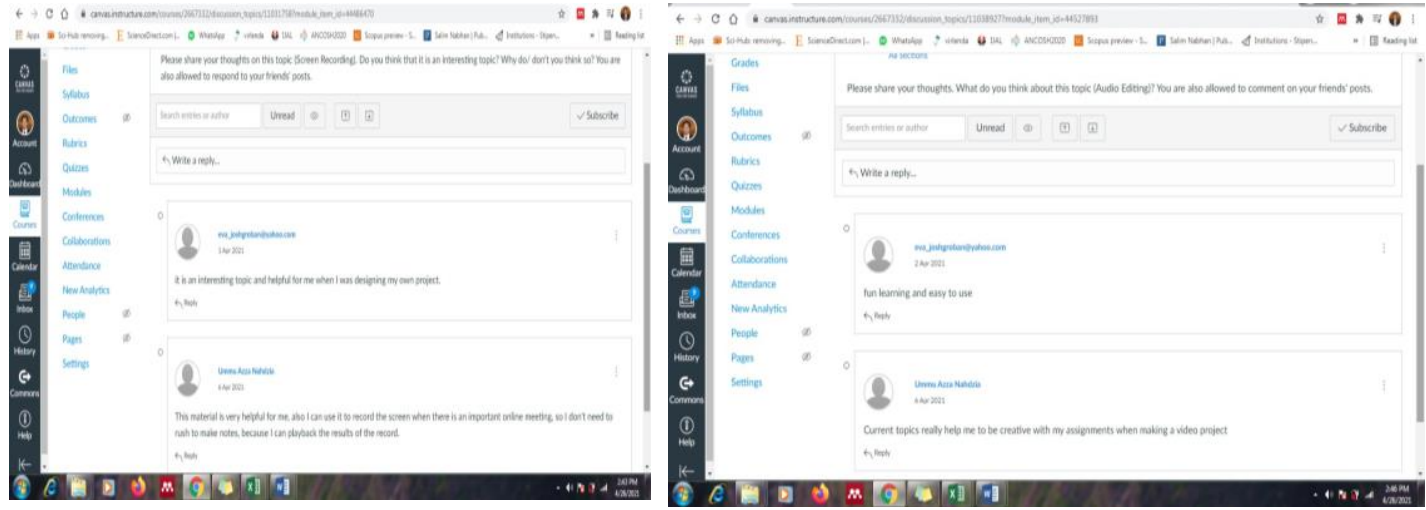

Gambar 1. Opini para peserta
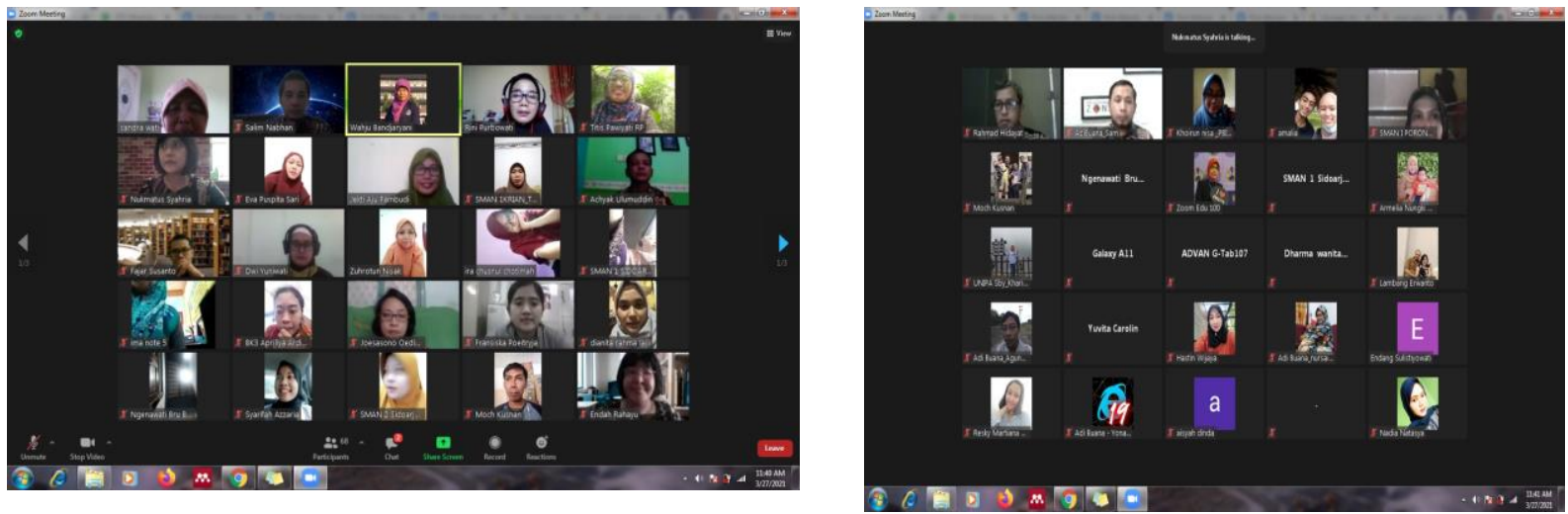

Gambar 2. Proses pelatihan Podcast dan Audacity

Media pembelajaran merupakan salah satu faktor utama yang menentukan keberhasilan sebuah proses pembelajaran. Media yang dikemas dengan menarik dapat membangkitkan motivasi siswa untuk meningkatkan minat belajar dan meningkatkan prestasi belajarnya, mempermudah proses belajar mengajar, membuat pembelajaran lebih efektif dan efisien. Aplikasi Audacity juga dapat membuat konten-konten yang ada di Podcast menjadi jauh lebih menarik. Aplikasi ini memungkinkan para siswa untuk mengedit audio serta menambahkan latar pada konten mereka berupa lagu ataupun efekefek suara lainnya. Penggunaan Podcast pada pembelajaran Listening dan Speaking terbukti 
merupakan suatu pembelajaran yang efektif, kreatif dan efisien. Hal ini sejalan dengan temuan penelitian dari Fitria et al., 2015, yang berpendapat bahwa Podcast merupakan alat pembelajaran berbasis teknologi yang inovatif dan kreatif yang efektif digunakan di kelas bahasa Inggris, terutama untuk meningkatkan kemampuan mendengarkan dan berbicara.

Selain menjadi sarana hiburan, Podcast atau aplikasi digital berformat audio juga dapat dijadikan media belajar bahasa asing. Yoestara \& Putri, 2019 dalam studinya berpendapat bahwa Podcast memberi banyak keuntungan bagi siswa dalam berlatih Listening dan Speaking. Hal ini dikarenakan Podcast memberikan ruang yang luas bagi siswa praktek menggunakan Bahasa Inggris secara langsung dengan menggunakan materi-materi yang up to date. Dalam hal menumbuhkan semangat belajar siswa untuk belajar secara aktif dan mandiri, Podcast juga dapat dijadikan sarana dalam meningkatkan kemandirian siswa dalam belajar serta meningkatkan rasa percaya diri siswa ketika praktek Listening \& Speaking. Podcast dapat mengurangi kecemasan siswa dan menstimulasi keinginan untuk bergabung dalam komunitas belajar (Chan et al., 2011).

Berikut adalah detail dari tahapan pembuatan Podcast yang dapat digunakan untuk pembelajaran Speaking dan Listening;

1. Download dan install aplikasi Podcast dari Google Play Store atau Apple App Store.

2. Buat akun baru

Setelah menginstal aplikasi Podcast, kita wajib membuat akun baru. Kita dapat langsung memakai akun Google kita dengan mengetik 'Continue with Google'.

3. Menentukan topik

Pastikan untuk mencari topik yang disukai, misalnya seperti "How to develop my speaking fluency", "How to raise our confident during public speaking", dan sebagainya. Penentuan topik ini dapat membantu memudahkan pembahasan. Untuk membuat orang lain tertarik untuk mendengarkan, kita harus dapat menciptakan gaya penyampaian yang unik dan kreatif. Disamping itu, topik yang kita siapkan juga harus yang up to date karena semakin banyak orang yang mendengarkan Podcast kita, pencapaian kita juga semakin baik. Hasil pencapaian tersebut dapat dilihat melalui platform yang disediakan oleh Podcast.

4. Menyiapkan alur

Setelah menentukan topik, kita dapat membuat alur untuk dijadikan pokok bahasan dalam siaran kita. Alur ini sangat penting untuk membantu memudahkan kita mengingat poin-poin penting yang akan dibicarakan dan agar kita tidak melenceng dari topik yang sudah kita buat.

\section{Merekam topik}

Kita dapat menekan tombol "Record" untuk membuat sebuah rekaman Podcast. Kita tidak perlu untuk menggunakan alat perekam yang mahal dan canggih untuk menghasilkan sebuah rekaman yang bagus, karena kita dapat mengedit audio kita nantinya, salah satunya yaitu dengan menggunakan aplikasi Audacity. Beri tanda "Flag" dengan menekan tombol "Add Flag" yang ada 
di aplikasi Podcast. Melalui fitur add flag ini, kita bisa mengedit kesalahan pengucapan atau kesalahan lain. Jika rekaman telah selesai, ketik tombol "Stop". Kita dapat meninjau hasil rekaman kita pada tombol "preview". Agar lebih menarik, kita dapat menghadirkan latar belakang iringan musik pada rekaman kita dengan memencet tombol "Add music".

6. Pencet tombol "Save" untuk menyimpan file audio kedalam akun kita. Dan kita dapat memberi judul pada file audio yang telah disimpan.

7. Pencet tombol "Publish" yang letaknya di pojok kanan atas untuk mulai menunggah rekaman Podcast yang sudah kita buat. Kita dapat mengubah jam atau hari untuk siaran Podcast kita dengan memencet tombol "Change publish date".

Agar lebih professional seperti seorang penyiar radio asli, kita dapat mengunggah hasil rekaman Podcast kita pada platform yang memang sudah ramai pendengar, seperti You Tube atau Soundcloud. Akan tetapi, ada biaya yang yang harus dibayar setiap bulannya saat kita ingin mengunggah Podcast kita di Soundcloud. Jika ingin memanfaatkan aplikasi yang gratis, kita dapat mengunggah rekaman kita ke platform Anchor.

Secara umum pengabdian yang dilakukan telah menunjukkan hasil yang positif terhadap penggunaan Podcast dalam pembelajaran Bahasa Inggris khususnya pembelajaran Listening dan Speaking. Oleh sebab itu, kami termotivasi untuk menerapkan Podcast dengan bantuan program Audacity untuk pengajaran Listening dan Speaking dalam program pelatihan pemanfaatan teknologi dalam pengajaran Bahasa Inggris bagi guru-guru SMA \& SMK kota Surabaya.

\section{KESIMPULAN}

Ada beberapa tahapan yang harus dilalui oleh pengguna Podcast ketika mereka ingin memanfaatkan aplikasi ini, mulai dari mendaftar sampai cara menggunakan aplikasi ini. Dari beberapa tahapan ini, tahapan perekaman adalah tahapan yang memungkinkan pengguna mengembangkan kreatifitasnya sesuai dengan isi dan tujuan dari materi yang ingin diunggah. Walau ada beberapa tahapan yang harus dilalui untuk bisa memanfaatkan Podcast, sebagian besar peserta sangat antusias membuat dan berlatih menggunakan aplikasi ini. Setelah mencoba dan memanfaatkan Podcast dengan bantuan Audacity, sebagian besar peserta mempunyai sikap yang positif terhadap penggunaan aplikasi Podcast dalam pengajaran Listening dan Speaking. Mereka mempunyai anggapan bahwa Podcast dapat membantu siswa melatih kedua keterampilan tersebut. Hal utama yang mendasari anggapan mereka adalah fleksibilitas serta kemudahan yang ditawarkan Podcast dalam penggunaannya.

\section{UCAPAN TERIMA KASIH}

Ucapan terima kasih yang sebesar-besarnya ditujukan kepada tim PPM Dosen Prodi Bahasa Inggris Universitas PGRI Adi Buana Surabaya beserta Ketua MGMP Bahasa Inggris SMA/SMK se-kota Surabaya dan para guru. Terima kasih juga ditujukan kepada Lembaga Penelitian dan Pengabdian 
Masyarakat Universitas PGRI Adi Buana Surabaya yang telah memberikan dukungan berupa dana pengabdian sehingga kegiatan kami dapat terselenggara dengan lancar.

\section{DAFTAR PUSTAKA}

Abdous, M., Camarena, M. M., \& Facer, B. R. (2009). MALL technology: Use of Academic podcasting in the foreign language classroom. ReCALL, 21(1), 76-95. https://doi.org/10.1017/S0958344009000020

Chan, W. M., Chi, S. W., Chin, K. N., \& Lin, C. Y. (2011). Students' perceptions of and attitudes towards podcast-based learning - A comparison of two language podcast projects. Electronic Journal of Foreign Language Teaching, 8, 312-335.

Fitria, U., Vianty, M., \& Petrus, I. (2015). Using Podcast To Improve Students' Listening and Speaking Achievements. Journal of English Literacy Education, 2(1), 55-68.

Karagiorgi, Y., \& Symeou, L. (2005). Translating constructivism into instructional design: Potential and limitations. Educational Technology and Society, 8(1), 17-27.

Ramli, A. mardila, \& Kurniawan, E. hari. (2018). The Use of Podcast to Improve Students' Listening and Speaking Skills for EFL Learners. 5(2), 1-10. https://doi.org/10.2991/iconelt-17.2018.42

Yoestara, M., \& Putri, Z. (2019). PODCAST: An alternative way to improve EFL students' listening and speaking performance. Englisia Journal, 6(1), 15. https://doi.org/10.22373/ej.v6i1.3805 